\title{
Shielding effects of myelin sheath on axolemma depolarization under transverse electric field stimulation
}

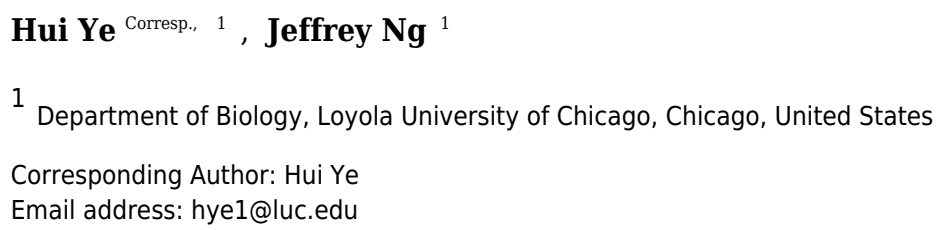

Axonal stimulation with electric currents is an effective method for controlling neural activity. An electric field parallel to the axon is widely accepted as the predominant component in the activation of an axon. However, recent studies indicate that the transverse component to the axolemma is also effective in depolarizing the axon. To quantitatively investigate the amount of axolemma polarization induced by a transverse electric field, we computed the transmembrane potential $(\mathrm{Vm})$ for a conductive body that represents an unmyelinated axon (or the bare axon between the myelin sheath in a myelinated axon). We also computed the transmembrane potential of the sheath-covered axonal segment in a myelinated axon. We then systematically analyzed the biophysical factors that affect axonal polarization under transverse electric stimulation for both the bare and sheath-covered axons. Geometrical patterns of polarization of both axon types were dependent on field properties (magnitude and field orientation to the axon). Polarization of both axons was also dependent on their axolemma radii and electrical conductivities. The myelin provided a significant "shielding effect" against the transverse electric fields, preventing excessive axolemma depolarization. Demyelination could allow for prominent axolemma depolarization in the transverse electric field, via a significant increase in myelin conductivity. This shifts the voltage drop of the myelin sheath to the axolemma. Pathological changes at a cellular level should be considered when electric fields are used for the treatment of demyelination diseases. The calculated term for membrane polarization $(V m)$ could be used to modify the current cable equation that describes axon excitation by an external electric field to account for the activating effects of both parallel and transverse fields surrounding the target axon. 
1 Shielding effects of myelin sheath on axolemma depolarization under transverse electric field 2 stimulation

3 Hui Ye, Jeffrey $\mathrm{Ng}$

4 Department of Biology, Loyola University Chicago, 1032 W. Sheridan Rd., Chicago, IL 60660

5 Correspondence:

6 Hui Ye, Ph.D.

7 Department of Biology

8 Loyola University Chicago

9 Quinlan Life Sciences Education and Research Center

1032 W. Sheridan Rd., Chicago, IL 60660

11 Tel (773) 508-2720

12 Hui Ye: hye1@1uc.edu

13

14

15

\section{ABSTRACT}

Axonal stimulation with electric currents is an effective method for controlling neural activity. An electric field parallel to the axon is widely accepted as the predominant component in the activation of an axon. However, recent studies indicate that the transverse component to the axolemma is also effective in depolarizing the axon. To quantitatively investigate the amount of axolemma polarization induced by a transverse electric field, we computed the transmembrane potential $(\mathrm{Vm})$ for a conductive body that represents an unmyelinated axon (or the bare axon between the myelin sheath in a myelinated axon). We also computed the transmembrane potential of the sheathcovered axonal segment in a myelinated axon. We then systematically analyzed the biophysical factors that affect axonal polarization under transverse electric stimulation for both the bare and sheath-covered axons. Geometrical patterns of polarization of both axon types were dependent on field properties (magnitude and field orientation to the axon). Polarization of both axons was also dependent on their axolemma radii and electrical conductivities. The myelin provided a significant "shielding effect" against the transverse electric fields, preventing excessive axolemma depolarization. Demyelination could allow for prominent axolemma depolarization in the transverse electric field, via a significant increase in myelin conductivity. This shifts the voltage 
drop of the myelin sheath to the axolemma. Pathological changes at a cellular level should be considered when electric fields are used for the treatment of demyelination diseases. The calculated term for membrane polarization $(\mathrm{Vm})$ could be used to modify the current cable equation that describes axon excitation by an external electric field to account for the activating effects of both parallel and transverse fields surrounding the target axon.

\section{INTRODUCTION}

Electrical stimulation of nerve cells was first reported by Luigi Galvani in 1780 (Galvani 1791), who accidently found that muscles from a dead frog would twitch when touched with a charged metal scalpel, a discovery that sparked the appreciation of electricity in relation to animation - or life. Today, electric stimulation of neurons in the peripheral or central nervous systems have been widely utilized for controlling neural network activity (Selimbeyoglu \& Parvizi 2010), synaptic transmission (Nowak \& Bullier 1998), and pain (Coderre et al. 1993). Electric currents can also be generated via magneto-electric induction with magnetic coils for non-invasive control of neural activity (Maccabee et al. 1991; Maccabee et al. 1993; Ye et al. 2011; Ye et al. 2010; Ye \& Steiger 2015).

An electric field surrounding a straight nerve axon can be separated into two components: one parallel to $\left(E_{/ /}\right)$and the other perpendicular (traversal, $\left.E_{\perp}\right)$ to the axon. The $E_{/ /}$is widely regarded as the predominant factor that activates the axons (Basser et al. 1992; Roth \& Basser 1990), which is supported by numerous experimental results (Amassian et al. 1989; Basser \& Roth 2000). Consequently, theoretical analyses of electrical activation have predominately been focused on computing $E_{/ /}$along a fiber (Esselle \& Stuchly 1994; Esselle \& Stuchly 1995; Nagarajan \& Durand 1995; Ravazzani et al. 1996; Roth \& Basser 1990; Roth et al. 1990). The current cable equation, $\lambda^{2} \frac{\partial^{2} \varphi_{m}}{\partial x^{2}}-\tau \frac{\partial \varphi_{m}}{\partial t}-\varphi_{m}=-\lambda^{2} \frac{\partial V_{e}}{\partial x^{2}}$, which describes axonal activation, contains only the axial term $\left(E_{/ /}\right)$. Here, $\lambda^{2}=\frac{R_{m} c}{2 R_{i}}$ and $\tau=R_{m} C_{m}$ are the space and time constants, respectively. $\varphi_{m}$ is the transmembrane potential and $V_{e}$ is the extracellular electric field applied to the fiber. It is nonzero only if $E_{/ /}$is nonzero. The surface resistance and capacitance of the membrane are $R_{m}$ and $C_{m}$, respectively. The intracellular resistivity is $R_{i}$ and the fiber radius is $c$. This simplification facilities the rapid calculation of neural activation. However, it ignores the presence of the cell, 
which perturbs the local extracellular electric field. It also ignores the mutual interactions between the neurons and the applied electric field (Ye \& Steiger 2015), mainly the electric field that directly penetrates and depolarizes the cell membrane, or $E_{\perp}$.

\section{Transversal field for membrane polarization}

Mounting evidence from experimental and simulation studies support the notion that cell membranes can be polarized by transversal electric fields. An electric field that penetrates the cell membrane was directly observed to cause polarization in hippocampal neurons (Bikson et al. 2001), in neural stem cells (Zhao et al. 2015), and in oocytes (Lee \& Grill 2005). When $E_{\perp}$ is extremely strong, it can even cause membrane instability and pore formation (Bingham et al. 2010). Analytical computations of the transverse membrane potential under electric stimulation started as early as the 1950s (Fricke 1953; Schwan 1957) for a simple cellular shape. Recent works have calculated membrane polarization by the transverse field in cells with more complex geometry (Kotnik \& Miklavcic 2000a; Kotnik \& Miklavcic 2000b), and by the transverse electric field induced by time-varying magnetic field (Ye et al. 2007; Ye et al. 2011).

Because of the observable, polarizing effects of the transverse field on large structures like the cell body, it is reasonable to speculate that a transverse field could also play a significant role in the polarization of axons. Indeed, evidence favoring transversal activation of axons also appear in the literature. It was reported (Pourtaheri et al. 2009) that individual axons can be selectively activated by a transverse field in a nerve bundle. These fields produce strong effects in the stimulation of ulnar nerves (Cros et al. 1990; Olney et al. 1990) and long fibers (Grill \& Wei 2009). Using a magnetic coil to induce the electric field, Ruohonen et al. (Ruohonen et al. 1996) discovered that activation of peripheral nerves could occur when the coil was oriented in a way that only generated $E_{\perp}$, and a later theoretical work (Ye et al. 2011) confirmed the axonal depolarization by this field. Clinically, the fast switching of magnetic fields during MRI scanning generates $E_{\perp}$ in patients, which is considered an important risk factor for unwanted peripheral nerve stimulation (While \& Forbes 2004).

At present, the consensus is that $E_{\perp}$ is a modulator to the dominant effects caused by $E_{/ /}$, although some researchers have speculated that the stimulation effects from transverse fields may arise due to nerve undulation, which generates longitudinal field components (Lontis et al. 2009; Schnabel \& Struijk 1999; Struijk \& Durand 1998). In the presence of $E_{/ /}$, it was thought that $E_{\perp}$ could introduce subthreshold membrane depolarization which enhances stimulation by providing 
89 an additive effect on $E_{/ /}$(Lontis et al. 2009). Alternatively, $E_{\perp}$ may provide rapid axonal 90 polarization in the transverse direction and $E_{/ /}$drives the slow development of the mean 91 transmembrane potential (Cranford et al. 2012). $E_{/ /}$and $E_{\perp}$ could potentially provide a strategy

92 for differential activation of axons with different properties (Ruohonen et al. 1996).

93 Modify cable equation to include the contribution of transverse field

94 In cases with significant transverse stimuli, where the membrane-field interaction is 95 sufficient and polarization is primarily due to the transverse field, the cable model assumptions are known to be invalid (Krassowska \& Neu 1994). Many modeling studies have argued for the inclusion of the transverse field for the accurate simulation of neural activation, as well as the development of mathematical tools to serve this purpose (Gimsa \& Wachner 2001; Kotnik \& Miklavcic 2000a; Kotnik \& Miklavcic 2006; Krassowska \& Neu 1994; Ye et al. 2011; Ye \& Steiger 2015).

Several papers have reported their first endeavors for modifying the cable equation. Yu et al. (Yu et al. 2005) modified the activation function to include the transversal field in magnetic stimulation. Ravazzani et al. magnetically stimulated the median nerve and recorded the evoked muscle responses, and discovered that including the transversal field in the cable equation provided a much improved correlation between the mush EMG and the activating function (Ravazzani et al. 1996). A recent endeavor, which modified the current cable equation to include the transversal term (Wang et al. 2018), showed that the transversal field could affect threshold of demyelinated axons, but not in myelinated axons. Another work by the same group included the transverse term in the cable equation that describes magnetic field stimulation (Wang 2018). In both these studies, the membrane was represented by a resistor in parallel with a membrane capacitance. For computational simplicity, all the above-mentioned works ignored the physical presence of the lipid bilayer membrane, a "shell" like structure that has non-zero thickness. Consequently, the field

113 perturbation caused by the membrane, which is essential for the re-distribution of the transverse 114 field proximal to the axon (Farkas et al. 1984) (Jerry et al. 1996) (Lee \& Grill 2005) (Mossop et al. 2007), as well as the buildup of transmembrane potential (Kotnik \& Miklavcic 2000a; Kotnik

116 \& Miklavcic 2000b) through cell-field interaction (Ye \& Steiger 2015), were ignored.

117 Furthermore, in the myelinated axon model, the possibility that the presence of the myelin sheath 118 might shield the internal structure such as the axon membrane (Kotnik \& Miklavcic 2006; Ye \& 119 Curcuru 2016) was not considered. 
In the present paper, we model a bare axon as a conductive cylindrical shell, and provide

121

122

123

124

125

126

127

128

129

130

131

132

133

134

135

136

137

138

139

140

141

142

143

144

145

146 an analytical expression of membrane polarization $(\mathrm{Vm})$ for an unmyelinated axon (or the node of Ranvier in myelinated axon), under transverse electric field stimulation. We also provide $V m$ for a myelin-covered axon, which was modeled as a co-centric, two shell structure. We investigate biophysical factors that may affect the $V m$, including field intensity and orientation, axonal biophysics and the impact of pathological demyelination. We discuss the possibility of placing $\mathrm{Vm}$ into a modified cable equation, so that the contributions of both the longitudinal and transverse components of an electrical field could be simultaneously evaluated during electric stimulation of axons.

\section{METHOD}

\section{Cylindrical axon model in a transverse electric field}

We modeled a bare axon and its myelin sheath using homogeneous cylindrical volume conductors (Esselle \& Stuchly 1994; Schnabel \& Struijk 2001). Figure 1A illustrates the location and orientation of a myelin-covered axon in a cylindrical coordinate system $(r, \theta, z)$. The axon was exposed to a transverse, direct current (DC) electric field $\left(E_{0}\right)$. It included a total of five isotropic and homogenous regions: the medium (\#0), the myelin sheath (\#1), the periaxonal space (\#2), the axolemma (\#3), and the axonal cytoplasm (\#4). The dielectric permittivities and conductivities in the five regions were $\varepsilon_{0}, \varepsilon_{1}, \varepsilon_{2}, \varepsilon_{3}, \varepsilon_{4}$ and $\sigma_{0}, \sigma_{1}, \sigma_{2}, \sigma_{3}, \sigma_{4}$, respectively. The myelin had an outer radius $(a)$, inner radius $(b)$ and the thickness $(b-a)$. The axon had an outer radius $(c)$ and inner radius $(d)$. Thickness of the axolemma was therefore $c-d$. Figure 1B illustrates a bare axon, which was composed of only the periaxonal space (\#2), the axolemma (\#3) and the axonal cytoplasm regions.

\section{Governing equation and boundary conditions}

Using the cylindrical coordinates $(r, \theta, z)$, the electric field distribution was calculated by

$$
\mathbf{E}=-\nabla V=-\left(\frac{\partial V}{\partial r}, \frac{1}{r} \frac{\partial V}{\partial \theta}, \frac{\partial V}{\partial z}\right)
$$

For the DC electric field stimulation, an electric potential was obtained by solving Laplace's equation

$$
\nabla^{2} V=0
$$


147 The potential, $V$, is the electric scalar potential due to the charge accumulation between the interface 148 of the two different media (Stratton 1941). In a cylindrical coordinate system $(r, \theta, z)$, it is written as

$$
\frac{1 \partial}{r \partial r}\left(r \frac{\partial V}{\partial r}\right)+\frac{1 \partial^{2} V}{r^{2} \partial \theta^{2}}=0
$$

150

151

152

153

154

155

156

157

158

159

160

161

162

163

164

165

166

167

168

169

170

171

Several boundary conditions were evaluated in solving the equation (Appendix): (A). The electric potential was continuous across the boundary of the two different media. (B). The normal current density was continuous across the two different media. "Complex conductivity", defined as $S=\sigma+j \omega \varepsilon$, was calculated to account for the dielectric permittivity of the material (Kotnik \& Miklavcic 2000b; Kotnik et al. 1998; Polk \& Song 1990). Here, $\sigma$ was the conductivity of the tissue, $\varepsilon$ was the permittivity, $\omega$ was the angular frequency of the field (zero for DC electric field) and $j=\sqrt{-1}$ was the imaginary unit. On the extracellular media/myelin interface $(\# 0 \# 1, r=a)$,

$$
S_{0} E_{0 r}-S_{1} E_{1 r}=0
$$

On the myelin /periaxonal interface $(\# 1 \# 2, r=b)$,

$$
S_{1} E_{1 r}-S_{2} E_{2 r}=0
$$

On the periaxonal/axon interface $(\# 2 \# 3, r=c)$,

$$
S_{2} E_{2 r}-S_{3} E_{3 r}=0
$$

On the axon/cytoplasm interface $(\# 3 \# 4, r=d)$,

$$
S_{3} E_{3 r}-S_{4} E_{4 r}=0
$$

where $S_{0}=\sigma_{0}+j \omega \varepsilon_{0}, S_{1}=\sigma_{1}+j \omega \varepsilon_{1}, S_{2}=\sigma_{2}+j \omega \varepsilon_{2}, S_{3}=\sigma_{3}+j \omega \varepsilon_{3}, S_{4}=\sigma_{4}+j \omega \varepsilon_{4}$.

Electric fields an infinite distance away should not be perturbed by presence of the axon. (D). The electric potential inside the cytoplasm $(r=0)$ was finite.

\section{Model parameters}

Table 1 lists the default values of the model parameters and their ranges. The choice of the electric parameters were based on reports in the literature (Kotnik et al. 1997; Kotnik \& Miklavcic 2006). Axon radius was selected from Berthold and Rydmark (Berthold \& Rydmark 1995). The diameter of the unmyelinated axons ranges from approximately $0.1 \mu \mathrm{m}$ to $2 \mu \mathrm{m}$ ( $3 \mu \mathrm{m}$ in humans). 
172 We used $0.6 \mu \mathrm{m}$ as the standard value and $0.1-3 \mu \mathrm{m}$ as the range. The thickness of the axonal 173 membrane was selected from Nagarajan and Durant (Nagarajan \& Durand 1995). The diameter of 174 the myelin was set to double the axon diameter. Lamella are produced by many layers of processes 175 from oligodendrocytes with significant membrane resistivity (Bakiri et al. 2011). The resistance of 176 the myelin was scaled linearly by the number $(n)$ of lamella (Chomiak \& Hu 2009). The standard 177 electric intensity was $200 \mathrm{~V} / \mathrm{m}$. The maximum intensity is the one that can cause membrane 178 electroporation (Sadik et al. 2011).

\section{Software packages}

Equations were derived with Mathematica 10 (Wolfram Research, Inc. Champaign, IL). Numerical simulations were performed with Matlab 8.4.0 (The MathWorks, Inc. Natick, MA).

\section{RESULTS}

Analytical expressions of axonal transmembrane potential $(\mathrm{Vm})$ and voltage drop on the myelin sheath $(\phi)$ under transverse electric stimulation

The solution for Laplace's equation (Eq. 3) was written in the form (Griffiths 1999)

187

188

189

190

191

192

193

194

195

196

197

$$
\begin{aligned}
& V(r, \theta)=A_{0} \ln (r)+B_{0}+ \\
& \sum_{n=1}^{\infty} r^{n}\left[A_{n} \sin (n \theta)+B_{n} \cos (n \theta)\right]+\sum_{n=-\infty}^{-1} r^{n}\left[C_{n} \sin (n \theta)+D_{n} \cos (n \theta)\right]
\end{aligned}
$$

The expression was further simplified for the five modeled regions (Griffiths 1999; Ye et al. 2011)

$$
V_{n}=\left(\frac{A_{n}}{r}+C_{n} r\right) \sin \theta
$$

where $A_{n}, C_{n}$ were unknown coefficients $(n=0,1,2,3,4)$. These coefficients were solved in the Appendix (Supplementary file 1), by considering boundary conditions (A)-(D). Substituting $A_{3}, C_{3}$ into (9), we obtained the expression of voltage inside the axolemma

$V_{3}=-\frac{8 a^{2} b^{2} c^{2} E_{0} S_{0} S_{1} S_{2} \cos \theta}{r}\left[\frac{\text { term } 1}{\text { term } 2+\text { term } 3}\right]$

\section{Where}

$\operatorname{term} 1=d^{2}\left(S_{3}-S_{4}\right)+r^{2}\left(S_{3}+S_{4}\right)$

term $2=b^{2}\left(S_{0}-S_{1}\right) \times$ 
198

199

200

201

202

203

204

205

206

207

208

209

210

211

212

213

$\emptyset=2 a(a-b) E_{0} S_{0}\left[\frac{\text { term } 5+\text { term } 6}{\text { term } 2+\text { term } 3}\right] \cos \theta$

Where

term $5=b\left\{c^{2}\left(S_{1}+S_{2}\right) \times\right.$

$$
\begin{gathered}
{\left[d^{2}\left(S_{2}+S_{3}\right)\left(-S_{3}+S_{4}\right)-c^{2}\left(S_{2}-S_{3}\right)\left(S_{3}+S_{4}\right)\right]-b^{2}\left(S_{1}-S_{2}\right)} \\
\left.\left[d^{2}\left(S_{2}-S_{3}\right)\left(S_{3}-S_{4}\right)+c^{2}\left(S_{2}+S_{3}\right)\left(S_{3}+S_{4}\right)\right]\right\}
\end{gathered}
$$

214

215

term $6=a\left\{c^{2}\left(S_{1}-S_{2}\right) \times\right.$

$$
\begin{array}{r}
{\left[d^{2}\left(S_{2}+S_{3}\right)\left(S_{3}-S_{4}\right)+c^{2}\left(S_{2}-S_{3}\right)\left(S_{3}+S_{4}\right)\right]+b^{2}\left(S_{1}+S_{2}\right)} \\
\left.\left[d^{2}\left(S_{2}-S_{3}\right)\left(S_{3}-S_{4}\right)+c^{2}\left(S_{2}+S_{3}\right)\left(S_{3}+S_{4}\right)\right]\right\}
\end{array}
$$

216

217

The axonal transmembrane potential $(\mathrm{Vm})$ of the field was obtained by subtracting 
218 parameters (conductivity and di-electricity) and the geometrical parameters (i.e., diameters of the

219 axon). The above $V m$ expression for the myelin-covered axon (Eq. 11) was further simplified for

220 a bare axon by assuming $\mathrm{S}_{1}=\mathrm{S}_{0}$ and $\mathrm{S}_{2}=\mathrm{S}_{0}$ (Supplementary file 3 ),

$221 \quad V_{m}=\frac{2 c(c-d) E_{0} S_{0}\left[d\left(-S_{3}+S_{4}\right)+c\left(S_{3}+S_{4}\right)\right]}{d^{2}\left(S_{0}-S_{3}\right)\left(S_{3}-S_{4}\right)+c^{2}\left(S_{0}+S_{3}\right)\left(S_{3}+S_{4}\right)} \cos \theta$

222

223

224

225

226

227

228

229

230

231

232

233

234

235

236

237

238

239

240

241

242

243

244

245

\section{Impact of electric field properties on $V m$}

When a transverse electric field penetrates the axolemma, the geometrical pattern of $\mathrm{Vm}$ is determined by the axon's orientation to the electric field. The axolemma should be hyperpolarized wherever an electric current enters the membrane and be depolarized wherever the current extrudes from the membrane (Ye \& Steiger 2015). We plotted the transmembrane potential for a $50 \mu \mathrm{m}$ myelinated axon (Figure 2A) and a straight bare axon (Figure 2B), based on the calculated $\mathrm{Vm}$ using standard values (Table 1). As expected, the locations of maximum polarization were at two lines corresponding to when $\theta=180^{\circ}$ (hyperpolarization, blue) and $\theta=0^{\circ}$ (depolarization, yellow), respectively. The axons were not polarized at the locations where $\theta=90^{\circ}$ and $\theta=270^{\circ}$.

When the axon was wrapped by a thick myelin sheath, the geometrical pattern of the axolemma depolarization (Figure 2A) remained identical to an unmyelinated axon (Figure 2B). However, since a large voltage gradient $(\phi)$ was generated on the myelin sheath rather than on the axolemma, $V m$ was quantitatively negligible for the myelinated axon. With the standard values in Table 1, the maximum $\phi$ was $0.6 \mathrm{mV}$ for the myelin sheath, and the maximum $V m$ was only $0.53 \times 10^{-2} \mu \mathrm{V}$ for the axolemma. In contrast, when the axon was not myelinated, the maximum $V m$ was $0.24 \mathrm{mV}$.

For both the myelin-covered and bare axons, $V m$ was proportional to the intensity of the electric field (Figures 2C and 2D). $2 \mathrm{kV} / \mathrm{cm}$ was sufficient in inducing electroporation (Sadik et al. 2011). This intensity induced a $V m$ of $5.3 \mu \mathrm{V}$ for the myelin-covered axon. For a bare axon, it induced a $V m$ of $239.9 \mathrm{mV}$, which is sufficient to break down the structure of the membrane (Gehl 2003; Kinosita \& Tsong 1977). These results suggest that the myelin sheath could provide a "shielding effect" on the axolemma against field-induced excessive polarization and structure disruption.

\section{Impact of axonal properties on $\mathrm{Vm}$}


We investigated the dependency of $V m$ on the axonal properties, including the geometrical

247 features (axon radius and membrane thickness) of the axon, and its conductivity. For the

248

249

250

251

252

253

254

255

256

257

258

259

260

261

262

263

264

265

266

267

268

269

270

271

272

273

274

275 parametric analysis, we plotted the maximum polarization $\left(\theta=0^{0}\right.$ on the axon surface, Figures 1 and 2) when one parameter was varied through its defined value range, while the others were maintained at their standard values.

An axon with a larger radius was associated with a greater $V m$ for both the myelin-covered axon and bare axon (Figure 3A) under a transverse field stimulation. Axon thickness, however, did not significantly affect $V m$ (Figure 3B). $V m$ was insensitive to the axonal conductance changes within its physiological range $\left(10^{-8}-10^{-6} \mathrm{~S} / \mathrm{m}\right)$, in agreement with the literature that studied spherical cell polarization in an electric field (Kotnik et al. 1997; Kotnik \& Miklavcic 2006). However, when axolemma conductivity was significantly increased $\left(>10^{-3} \mathrm{~S} / \mathrm{m}\right)$ due to membrane disruption and leakage, such as during electroporation (Mossop et al. 2007; Mossop et al. 2004), axolemma depolarization decreased significantly for both the myelin-covered and bare axons (Figure 3C).

\section{Impact of demyelination on axonal $\mathrm{Vm}$}

Myelin, like a neuronal cell membrane, is constructed of a lipid bilayer that contains a hydrophobic center and hydrophilic surface. Myelin wraps around an axon numerous times, each layer acting like multiple resistors in series. Demyelination occurs in many neurological diseases such as spinal cord injury (Ye et al. 2012), cerebral palsy (Ruff et al. 2013) and multiple sclerosis (Lazzarini 2004). Demyelination is defined by the significant loss of myelin thickness (Mainero et al. 2015; Manogaran et al. 2016) and increased conductivity of the myelin.

We first studied how the loss of myelin layers could affect $V m$ in a transverse electric field. We systematically decreased the myelin thickness from $4.0 \mu \mathrm{m}$ to $0.1 \mu \mathrm{m}$. The conductivity of the myelin increased linearly with the reduction of the myelin thickness. This caused a reduction in the potential drop across the myelin sheath, but it did not significantly affect axonal depolarization (Figure 4). The transverse electric field was ineffective in inducing axonal depolarization, assuming the remaining myelin sheath could maintain low conductivity $\left(\sim 10^{-7} \mathrm{~S} / \mathrm{m}\right)$.

We then investigated how an increase of myelin conductivity could affect $V m$ in a transverse electric field. When myelin conductivity was as low as $5 \times 10^{-5} \mathrm{~S} / \mathrm{m}$, reduction in myelin 
276 thickness did not lead to dramatic changes in $V m$ (Figure 5A). Instead, it led to a voltage drop

277 across the myelin sheath $(\phi)$. When myelin conductivity was increased to $5 \times 10^{-3} \mathrm{~S} / \mathrm{m}, V m$ could

278 exceed $\phi$ for an extremely thin myelin sheath (Figure 5B). For a very leaky myelin (myelin

279 conductivity is $5 \times 10^{-1} \mathrm{~S} / \mathrm{m}$ ), the axon could be significantly depolarized at any myelin thickness

280 (Figure 5C), and $\mathrm{Vm}$ could be greater than $\phi$ for a thin myelin sheath (Figure 5C, left inset).

281 However, $\phi$ still dominated for axons with thick myelin sheaths (Figure 5C, right inset). In

282 conclusion, demyelination could cause a re-distribution of the potentials between the axolemma

283 and myelin under transverse electric stimulation. Increases in myelin conductivity during

284 demyelination could cause the voltage distribution to shift from the myelin sheath to the axon.

285 Axonal depolarization became prominent when significant reduction of myelin conductivity

286 occurred during demyelination.

\section{DISCUSSION}

288 This work provides a novel analytical expression that describes the membrane polarization 289 of axons (myelinated and bare) under transverse field stimulation. It analyzes the biophysical 290 factors that affect axonal polarization under physiological conditions, and under pathological 291 conditions such as demyelination. Finally, it provides the needed term to modify the current cable 292 equation, so that the equation can account for the effects of more realistic field, which include both 293 the transverse and parallel directions.

\section{Impact of field orientation on $\boldsymbol{V m}$ in transverse current stimulation}

The model shows that the longitudinal axon was polarized with a distinct geometrical pattern by the transverse electric field, which was dependent on the orientation of the axon in the field. Previously, regional polarization has been observed in a variety of modeling and experimental studies for cells under electric (Durand 2003; Lee \& Grill 2005; Lu et al. 2008; Teruel \& Meyer 1997) and magnetic field stimulation (Schnabel \& Struijk 1999; Schnabel \& Struijk 2001; Ye et al. 2007). Functionally, orientation of the electric field to the axon is important for the excitation of axons, such as those from the retina ganglion cells (Grumet et al. 2000). Since only a small patch of membrane is depolarized in the transverse field, it is reasonable to speculate that voltage gated ion channels may have a diverse response to the field, depending on their location on the membrane patch. This could cause the threshold for activation to be higher than that observed from axons in longitudinal fields that induce the same peak depolarization (Schnabel \& 
306 Struijk 2001). The higher threshold may explain the relative poor efficiency of axonal activation

307 by transverse field stimulation (McNeal 1976; Ranck 1975).

308

309

310

311

312

313

314

315

316

317

318

319

320

321

322

323

324

325

326

327

328

329

330

331

332

333

334

335

\section{Impact of axon's biophysical properties on $\boldsymbol{V} \boldsymbol{m}$}

We found that $V m$ was dependent on the intrinsic tissue properties of an axon. We observed that $V m$ was greater in larger diameter axons than in smaller ones (Figure 3A). This observation is in agreement with the notion that larger diameter axons are associated with lower excitation thresholds (Basser \& Roth 1991; Carbunaru \& Durand 1997; Garnsworthy et al. 1988; Reilly 1989). Selective activation of different size fibers has significant clinical implications, such as pain relief (Meyerson \& Linderoth 2000), which can be achieved by novel design of the electric field (Konings 2007). In deep brain stimulation (DBS), the effects of the electric currents within different brain regions were dependent on the fiber sizes (Sotiropoulos \& Steinmetz 2007). In addition, an increase in axolemma conductivity decreases the axon's sensitivity (buildup of $\mathrm{Vm}$ ) to the transverse field (Figure 3C), suggesting a shunting effect to the transverse current. In conclusion, the effectiveness of transverse stimulation relies on the physiological features of the target axon.

Axonal diameter could change under certain pathological situations. For example, axon swelling occurs during focal demyelination (Kolaric et al. 2013), as a consequence of aglycemia (Allen et al. 2006), anoxia (Waxman et al. 1992) or ischemia (Garthwaite et al. 1999). It is speculated that these pathological changes could potentially render the enlarged axons more sensitive to the transverse electric field.

\section{Impact of demyelination and other pathological conditions on $V m$ in transverse electric stimulation}

Dynamic changes of myelin occur during demyelination. It is unknown if pathological demyelination could affect the sensitivity of a myelinated axon to a transverse electric field. While myelin-covered axons could only be slightly depolarized by the transverse field, bare axons can have a moderate buildup of $V m$ (Figure 2), especially when the axon diameter is large (Figure 5A). We used the model to test two possibilities of reduced myelination and their impacts on $\mathrm{Vm}$. Reduction in the myelin thickness, along with a scaled linear increase in myelin conductance, was not sufficient to enhance depolarization (Figure 4). In contrast, $V m$ was enhanced when the myelin 
336 sheath became electrically leaky (highly conductive) (Figure 5). It is therefore expected that 337 transverse electric fields could apply variable axonal depolarization, depending on the myelin

338

339

340

341

342

343

344

345

346

347

348

349

350

351

352

353

354

355

356

357

358

359

360

361

362

363

conductivity changes during the process of demyelination. Electrical stimulation protocols for the treatment of demyelination diseases (Dooley \& Sharkey 1981; Dooley et al. 1978) could be further optimized by considering remyelination/demyelination factors during treatment, to ensure maximum outcomes.

Dynamic changes of myelin also occur during development (Sturrock 1980), neural regeneration (Huang et al. 2013), and pathological situations such as traumatic brain injury (Robain \& Mandel 1974; Tyler 2012). At the cellular level, membrane resistance of the oligodendrocyte could change during development and maturity (Karadottir et al. 2005), and in a medium with low osmolarity (Kimelberg \& Kettenmann 1990). It is speculated that these dynamic changes in the myelin properties could cause the axons to react differently to the electric field. This supports the notion that the dynamic interaction between the electric field and the neuronal tissue, as well as the outcome of the stimulation, are determined by both the electric parameters and the tissue properties (Ye \& Steiger 2015).

\section{Modification of the cable equation to include the transverse field}

The analytical expression of the $V m$ term could potentially be used to modify the current cable equation to account for both $E_{/ /}$and $E_{\perp}$. Ruohonen et al. modified the cable equation (Ruohonen et al. 1996) to be in the form of $\lambda^{2} \frac{\partial^{2} \varphi_{m}}{\partial x^{2}}-\tau \frac{\partial \varphi_{m}}{\partial t}-\varphi_{m}-2 c\left(\alpha E_{/ /}^{\prime}-E_{\perp}\right)=0$. Here, $\alpha E_{/ /}^{\prime}-E_{\perp}$ is interpreted as the modified activating function, where $\alpha=\frac{\lambda^{2}}{2 c}=\frac{R_{m}}{4 R_{i}}$ (Ruohonen et al. 1996). Comparatively large values of $\alpha$ indicates that $E_{/ /}^{\prime}$ is responsible for the majority of excitation, while $\alpha=0$ indicates that $E_{\perp}$ is more important.

In this modified equation, the term $2 c E_{\perp}$ is the membrane potential created by the transverse field. For magnetic stimulation, an analytical expression (Ye et al. 2011) is available to replace this term for the modified cable equation. For direct electric stimulation, the $\mathrm{Vm}$ term for the unmyelinated axon (Eq. 13) can be used to replace the $2 c E_{\perp}$ term, to include the impact of the transverse electric field. Previously, effects of the transverse field and the axial field have been compared in several works (Lontis et al. 2009; Ruohonen et al. 1996; Yu et al. 2005). The 
364 transverse electric field is required to be several times greater than the longitudinal field to produce 365 comparable results (McNeal 1976; Ranck 1975; Ruohonen et al. 1996). A precondition for the 366 modified activation function to yield accurate results is for the electric field to be approximately 367 uniform and be perpendicular to the axon fiber (Schnabel \& Struijk 2001), which is readily 368 satisfied in our model.

369

370

\section{Limitations and future directions}

This paper was not intended to fully elucidate the mechanisms behind transverse field activation of nerve tissue, since it did not include any ionic channel mechanisms. The model also does not necessarily apply to the stimulation of fiber bundles. Axons within a bundle could interfere with other axon's polarization under a transverse electric field (Pourtaheri et al. 2009). Local electric fields could be perturbed by an axon, which produces a small, secondary effect on the surrounding axons (Lee \& Grill 2005; Susil et al. 1998). In a nerve bundle, Vm could also be a function of the anisotropy of the bundle (Nagarajan \& Durand 1995), which was not studied in the present model. Finally, the transverse field could be significantly weaker due to the lower values of conductance of surrounding perineurium (Struijk \& Schnabel 2001). More complicated modeling work should resort to numerical methods, whose accuracy can be validated by the analytical results from this work.

The model predicts that the node section in a myelinated axon will have the same polarization as the unmyelinated axon. If one considers that the node has a much higher density of $\mathrm{Na}^{+}$channel distribution (Freeman et al. 2016), it is predicted that myelinated axons will have a lower threshold of activation under transverse electric field. This model prediction could be tested by stimulating a structure that contains both unmyelinated and myelinated axons, such as the corpus callosum (Crawford et al. 2009; Ruff et al. 2013). With the strong stimulus being applied on both type of axons (Ruff et al. 2013), action potentials should be triggered first in the myelinated axons.

\section{Conclusions}

This work provides novel analytical expressions of the electrically-induced transmembrane potential $(\mathrm{Vm})$ for a myelin-covered axon and a bare, unmyelinated axon, under a transverse DC electric field. Results show that the myelin sheath shields the axon from extensive depolarization. 
394 Demyelination could alter axon's sensitivity to a transverse electric field if the process of 395 demyelination involves significant increases in the electric conductance of the myelin. The 396 analytical solution of $V m$ for the unmyelinated axon can be used to improve the activation function 397 of the current cable equation that describes electric stimulation.

398

399 Acknowledgements:

400 The authors thanks Austen Curcuru for the assistance in deriving the equations.

401

402

403

Appendix - Determining unknown coefficients $A_{n}, C_{n}$ in equation (9) using boundary conditions (A)-(D)

404

At an infinite distance, according to boundary condition (C), $V_{o}=-E_{0} r \cos \theta$. Therefore, 405 $a_{0}=-E_{0}$. Since $\mathrm{V}$ was bounded at $r=0$ (boundary condition $\mathrm{D}$ ), $C_{4}=0$.

406

Expressions for the potential distribution in the five modeled regions were:

$407 \quad V_{0}=-E_{0} r \cos \theta+\frac{C_{0}}{r} \cos \theta$

$408 V_{1}=A_{1} r \cos \theta+\frac{C_{1}}{r} \cos \theta$

$409 \quad V_{2}=A_{2} r \cos \theta+\frac{C_{2}}{r} \cos \theta$

$410 \quad V_{3}=A_{3} r \cos \theta+\frac{C_{3}}{r} \cos \theta$

$411 V_{4}=A_{4} r \cos \theta \quad(\mathrm{A}-5)$

412 The $\dot{r}$ components of $\nabla V$ (from Eq. 1) were continuous across the interfaces (boundary condition $413 \mathrm{~A}$ ), and the normal components of the current density were continuous across the interfaces 414 (boundary condition B). These boundary conditions yield the following set of equations: 
415 On the $\# 0 \# 1$ interface $(\mathrm{r}=\mathrm{a})$

$416-E_{0} a+\frac{C_{0}}{a}=a A_{1}+\frac{C_{1}}{a}$

$417 \quad S_{0}\left(-E_{0}-\frac{C_{0}}{a^{2}}=S_{1}\left(A_{1}-\frac{C_{11}}{a^{2}}\right)\right.$

418 On the \#1\#2 interface $(r=b)$

$419 \quad b A_{1}+\frac{C_{1}}{b}=b A_{2}+\frac{C_{2}}{b}$

420

$S_{1}\left(A_{1}-\frac{C_{1}}{b^{2}}\right)=S_{2}\left(A_{2}-\frac{C_{2}}{b^{2}}\right)$

421 On the \#2\#3 interface $(\mathrm{r}=\mathrm{c})$

$422 \quad c A_{2}+\frac{C_{2}}{c}=c A_{3}+\frac{C_{3}}{c}$

$423 \quad S_{2}\left(A_{2}-\frac{C_{2}}{c^{2}}\right)=S_{3}\left(A_{3}-\frac{C_{3}}{c^{2}}\right)$

424 On the \#3\#4 interface $(r=d)$

$425 d A_{3}+\frac{C_{3}}{d}=d A_{4}$

426

$S_{3}\left(A_{3}-\frac{C_{3}}{d^{2}}\right)=S_{4} A_{4}$

427

We solved (A-6) to (A-13) to obtain the unknown coefficients (Supplementary file 1). These

428 coefficients will be substituted into (A-1) to (A-5) to obtain the analytical expression of the

429 voltages in the five regions (Supplementary file 1).

\section{List of Abbreviations}

431 DC: Direct current; $E_{0}$ : Intensity of the externally applied DC electric field $(\mathrm{V} / \mathrm{m}) ; V m$ :

432 Transmembrane potential induced by the DC electric field across the axolemma (mV); $\phi$ : Potential 
433 drop across the myelin sheath $(\mathrm{mV}) ; E_{/ /}:$Electric field that is parallel to the axon; $E_{\perp}:$ Electric

434 field that is perpendicular (traversal) to the axon.

435

436

437

438

439

440

441

442

443

444

445

446

447

448

449

450

451

452

453

454

455

456

457

458

459

460

461

462

463

464

465

466

467

468

469

470

471

472

473

474

475

476

477

\section{References}

Allen L, Anderson S, Wender R, Meakin P, Ransom BR, Ray DE, and Brown AM. 2006. Fructose supports energy metabolism of some, but not all, axons in adult mouse optic nerve. J Neurophysiol 95:1917-1925. 10.1152/jn.00637.2005

Amassian VE, Maccabee PJ, and Cracco RQ. 1989. Focal stimulation of human peripheral nerve with the magnetic coil: a comparison with electrical stimulation. Exp Neurol 103:282-289.

Bakiri Y, Karadottir R, Cossell L, and Attwell D. 2011. Morphological and electrical properties of oligodendrocytes in the white matter of the corpus callosum and cerebellum. J Physiol 589:559573. 10.1113/jphysiol.2010.201376

Basser PJ, and Roth BJ. 1991. Stimulation of a myelinated nerve axon by electromagnetic induction. Med Biol Eng Comput 29:261-268.

Basser PJ, and Roth BJ. 2000. New currents in electrical stimulation of excitable tissues. Annu Rev Biomed Eng 2:377-397. 10.1146/annurev.bioeng.2.1.377

Basser PJ, Wijesinghe RS, and Roth BJ. 1992. The activating function for magnetic stimulation derived from a three-dimensional volume conductor model. IEEE Trans Biomed Eng 39:1207-1210. $10.1109 / 10.168686$

Berthold CH, and Rydmark M. 1995. Morphology of Normal Peripheral Axon. In: Waxman SG, Kocsis JD, and Stys PK, eds. The Axon: Structure, Function, and Pathophysiology: Oxford University Press US.

Bikson M, Lian J, Hahn PJ, Stacey WC, Sciortino C, and Durand DM. 2001. Suppression of epileptiform activity by high frequency sinusoidal fields in rat hippocampal slices. J Physiol 531:181-191.

Bingham RJ, Olmsted PD, and Smye SW. 2010. Undulation instability in a bilayer lipid membrane due to electric field interaction with lipid dipoles. Phys Rev E Stat Nonlin Soft Matter Phys 81:051909. 10.1103/PhysRevE.81.051909

Carbunaru R, and Durand DM. 1997. Axonal stimulation under MRI magnetic field z gradients: a modeling study. Magn Reson Med 38:750-758.

Chomiak T, and Hu B. 2009. What is the optimal value of the g-ratio for myelinated fibers in the rat CNS? A theoretical approach. PLoS One 4:e7754. 10.1371/journal.pone.0007754

Coderre TJ, Katz J, Vaccarino AL, and Melzack R. 1993. Contribution of central neuroplasticity to pathological pain: review of clinical and experimental evidence. Pain 52:259-285.

Cranford JP, Kim BJ, and Neu WK. 2012. Asymptotic model of electrical stimulation of nerve fibers. Med Biol Eng Comput 50:243-251. 10.1007/s11517-012-0870-3

Crawford DK, Mangiardi M, and Tiwari-Woodruff SK. 2009. Assaying the functional effects of demyelination and remyelination: revisiting field potential recordings. $J$ Neurosci Methods 182:25-33. 10.1016/j.jneumeth.2009.05.013

Cros D, Day TJ, and Shahani BT. 1990. Spatial dispersion of magnetic stimulation in peripheral nerves. Muscle Nerve 13:1076-1082. 10.1002/mus.880131110

Dooley DM, and Sharkey J. 1981. Electrical stimulation of the spinal cord in patients with demyelinating and degenerative diseases of the central nervous system. Appl Neurophysiol 44:218-224.

Dooley DM, Sharkey J, Keller W, and Kasprak M. 1978. Treatment of demyelinating and degenerative diseases by electro stimulation of the spinal cord. Med Prog Technol 6:1-14.

Durand DM. 2003. Electric field effects in hyperexcitable neural tissue: a review. Radiat Prot Dosimetry 106:325-331. 
478

479

480

481

482

483

484

485

486

487

488

489

490

491

492

493

494

495

496

497

498

499

500

501

502

503

504

505

506

507

508

509

510

511

512

513

514

515

516

517

518

519

520

521

522

523

524

525

Esselle KP, and Stuchly MA. 1994. Quasi-static electric field in a cylindrical volume conductor induced by external coils. IEEE Trans Biomed Eng 41:151-158. 10.1109/10.284926

Esselle KP, and Stuchly MA. 1995. Cylindrical tissue model for magnetic field stimulation of neurons: effects of coil geometry. IEEE Trans Biomed Eng 42:934-941. 10.1109/10.412660

Farkas DL, Korenstein R, and Malkin S. 1984. Electrophotoluminescence and the electrical properties of the photosynthetic membrane. I. Initial kinetics and the charging capacitance of the membrane. Biophys J 45:363-373. 10.1016/S0006-3495(84)84160-0

Freeman SA, Desmazieres A, Fricker D, Lubetzki C, and Sol-Foulon N. 2016. Mechanisms of sodium channel clustering and its influence on axonal impulse conduction. Cell Mol Life Sci 73:723-735. 10.1007/s00018-015-2081-1

Fricke H. 1953. The Electric Permittivity of a Dilute Suspension of Membrane-Covered Ellipsoids. J Appl Phys 24:644-646.

Galvani A. 1791. De viribus electricitatis in motu musculari commentaries. Opuscula:363-418.

Garnsworthy RK, Gully RL, Kenins P, and Westerman RA. 1988. Transcutaneous electrical stimulation and the sensation of prickle. J Neurophysiol 59:1116-1127.

Garthwaite G, Brown G, Batchelor AM, Goodwin DA, and Garthwaite J. 1999. Mechanisms of ischaemic damage to central white matter axons: a quantitative histological analysis using rat optic nerve. Neuroscience 94:1219-1230.

Gehl J. 2003. Electroporation: theory and methods, perspectives for drug delivery, gene therapy and research. Acta Physiol Scand 177:437-447. 10.1046/j.1365-201X.2003.01093.x

Gimsa J, and Wachner D. 2001. Analytical description of the transmembrane voltage induced on arbitrarily oriented ellipsoidal and cylindrical cells. Biophys J 81:1888-1896. 10.1016/S00063495(01)75840-7

Griffiths DJ. 1999. Introduction to Electrodynamics. 3rd Edition: Prentice Hall.

Grill WM, and Wei XF. 2009. High efficiency electrodes for deep brain stimulation. Conf Proc IEEE Eng Med Biol Soc 2009:3298-3301. 10.1109/IEMBS.2009.5333774

Grumet AE, Wyatt JL, Jr., and Rizzo JF, 3rd. 2000. Multi-electrode stimulation and recording in the isolated retina. J Neurosci Methods 101:31-42. S0165-0270(00)00246-6

Huang J, Zhang Y, Lu L, Hu X, and Luo Z. 2013. Electrical stimulation accelerates nerve regeneration and functional recovery in delayed peripheral nerve injury in rats. Eur J Neurosci 38:3691-3701. 10.1111/ejn.12370

Jerry RA, Popel AS, and Brownell WE. 1996. Potential distribution for a spheroidal cell having a conductive membrane in an electric field. IEEE Trans Biomed Eng 43:970-972. $10.1109 / 10.532132$

Karadottir R, Cavelier P, Bergersen LH, and Attwell D. 2005. NMDA receptors are expressed in oligodendrocytes and activated in ischaemia. Nature 438:1162-1166. 10.1038/nature04302

Kimelberg HK, and Kettenmann H. 1990. Swelling-induced changes in electrophysiological properties of cultured astrocytes and oligodendrocytes. I. Effects on membrane potentials, input impedance and cell-cell coupling. Brain Res 529:255-261.

Kinosita K, Jr., and Tsong TY. 1977. Voltage-induced pore formation and hemolysis of human erythrocytes. Biochim Biophys Acta 471:227-242.

Kolaric KV, Thomson G, Edgar JM, and Brown AM. 2013. Focal axonal swellings and associated ultrastructural changes attenuate conduction velocity in central nervous system axons: a computer modeling study. Physiol Rep 1:e00059. 10.1002/phy2.59

Konings MK. 2007. A new method for spatially selective, non-invasive activation of neurons: concept and computer simulation. Med Biol Eng Comput 45:7-24. 10.1007/s11517-006-0136-z

Kotnik T, Bobanovic F, and Miklavcic D. 1997. Sensitivity of Transmembrane Voltage Induced by Applied Electric Fields-A Theoretical Analysis. Bioelectrochem Bioenerg 43:285-291. 
526

Kotnik T, and Miklavcic D. 2000a. Analytical description of transmembrane voltage induced by electric fields on spheroidal cells. Biophys J 79:670-679. 10.1016/S0006-3495(00)76325-9

Kotnik T, and Miklavcic D. 2000b. Second-order model of membrane electric field induced by alternating external electric fields. IEEE Trans Biomed Eng 47:1074-1081. 10.1109/10.855935

Kotnik T, and Miklavcic D. 2006. Theoretical evaluation of voltage inducement on internal membranes of biological cells exposed to electric fields. Biophys J 90:480-491. 10.1529/biophysj.105.070771

Kotnik T, Miklavcic D, and Slivnik T. 1998. Time course of transmembrane voltage induced by timevarying electric field - a method for theoretical analysis and its application. Bioelectrochem Bioenerg 45:3-16.

Krassowska W, and Neu JC. 1994. Response of a single cell to an external electric field. Biophys J 66:1768-1776. 10.1016/S0006-3495(94)80971-3

Lazzarini RA. 2004. Myelin biology and disorders. San Diego: Elsevier Academic.

Lee DC, and Grill WM. 2005. Polarization of a spherical cell in a nonuniform extracellular electric field. Ann Biomed Eng 33:603-615.

Lontis ER, Nielsen K, and Struijk JJ. 2009. In vitro magnetic stimulation of pig phrenic nerve with transverse and longitudinal induced electric fields: analysis of the stimulation site. IEEE Trans Biomed Eng 56:500-512. 10.1109/TBME.2008.2009929

Lu H, Chestek CA, Shaw KM, and Chiel HJ. 2008. Selective extracellular stimulation of individual neurons in ganglia. J Neural Eng 5:287-309. 10.1088/1741-2560/5/3/003

Maccabee PJ, Amassian VE, Cracco RQ, Eberle LP, and Rudell AP. 1991. Mechanisms of peripheral nervous system stimulation using the magnetic coil. Electroencephalogr Clin Neurophysiol Suppl 43:344-361.

Maccabee PJ, Amassian VE, Eberle LP, and Cracco RQ. 1993. Magnetic coil stimulation of straight and bent amphibian and mammalian peripheral nerve in vitro: locus of excitation. J Physiol 460:201219.

Mainero C, Louapre C, Govindarajan ST, Gianni C, Nielsen AS, Cohen-Adad J, Sloane J, and Kinkel RP. 2015. A gradient in cortical pathology in multiple sclerosis by in vivo quantitative $7 \mathrm{~T}$ imaging. Brain 138:932-945. 10.1093/brain/awv011

Manogaran P, Vavasour IM, Lange AP, Zhao Y, McMullen K, Rauscher A, Carruthers R, Li DK, Traboulsee $\mathrm{AL}$, and Kolind SH. 2016. Quantifying visual pathway axonal and myelin loss in multiple sclerosis and neuromyelitis optica. Neuroimage Clin 11:743-750. 10.1016/j.nicl.2016.05.014

McNeal DR. 1976. Analysis of a model for excitation of myelinated nerve. IEEE Trans Biomed Eng 23:329337.

Meyerson BA, and Linderoth B. 2000. Mechanisms of spinal cord stimulation in neuropathic pain. Neurol Res 22:285-292.

Mossop BJ, Barr RC, Henshaw JW, and Yuan F. 2007. Electric fields around and within single cells during electroporation-a model study. Ann Biomed Eng 35:1264-1275. 10.1007/s10439-007-9282-1

Mossop BJ, Barr RC, Zaharoff DA, and Yuan F. 2004. Electric fields within cells as a function of membrane resistivity--a model study. IEEE Trans Nanobioscience 3:225-231.

Nagarajan SS, and Durand DM. 1995. Analysis of magnetic stimulation of a concentric axon in a nerve bundle. IEEE Trans Biomed Eng 42:926-933. 10.1109/10.412659

Nowak LG, and Bullier J. 1998. Axons, but not cell bodies, are activated by electrical stimulation in cortical gray matter. I. Evidence from chronaxie measurements. Exp Brain Res 118:477-488.

Olney RK, So YT, Goodin DS, and Aminoff MJ. 1990. A comparison of magnetic and electrical stimulation of peripheral nerves. Muscle Nerve 13:957-963. 10.1002/mus.880131012

Polk C, and Song JH. 1990. Electric fields induced by low frequency magnetic fields in inhomogeneous biological structures that are surrounded by an electric insulator. Bioelectromagnetics 11:235249. 
574

575

576

577

578

579

580

581

582

583

584

585

586

587

588

589

590

591

592

593

594

595

596

597

598

599

600

601

602

603

604

605

606

607

608

609

610

611

612

613

614

615

616

617

618

619

620

621

Pourtaheri N, Ying W, Kim JM, and Henriquez CS. 2009. Thresholds for transverse stimulation: fiber bundles in a uniform field. IEEE Trans Neural Syst Rehabil Eng 17:478-486.

10.1109/TNSRE.2009.2033424

Ranck JB, Jr. 1975. Which elements are excited in electrical stimulation of mammalian central nervous system: a review. Brain Res 98:417-440.

Ravazzani P, Ruohonen J, Grandori F, and Tognola G. 1996. Magnetic stimulation of the nervous system: induced electric field in unbounded, semi-infinite, spherical, and cylindrical media. Ann Biomed Eng 24:606-616.

Reilly JP. 1989. Peripheral nerve stimulation by induced electric currents: exposure to time-varying magnetic fields. Med Biol Eng Comput 27:101-110.

Robain O, and Mandel P. 1974. [Quantitative study of myelination and axonal growth in corpus callosum and posterior columns of spinal cord in the Jimpy mouse (author's transl)]. Acta Neuropathol 29:293-309.

Roth BJ, and Basser PJ. 1990. A model of the stimulation of a nerve fiber by electromagnetic induction. IEEE Trans Biomed Eng 37:588-597. 10.1109/10.55662

Roth BJ, Cohen LG, Hallett M, Friauf W, and Basser PJ. 1990. A theoretical calculation of the electric field induced by magnetic stimulation of a peripheral nerve. Muscle Nerve 13:734-741. $10.1002 /$ mus.880130812

Ruff CA, Ye H, Legasto JM, Stribbell NA, Wang J, Zhang L, and Fehlings MG. 2013. Effects of adult neural precursor-derived myelination on axonal function in the perinatal congenitally dysmyelinated brain: optimizing time of intervention, developing accurate prediction models, and enhancing performance. J Neurosci 33:11899-11915. 10.1523/JNEUROSCI.1131-13.2013

Ruohonen J, Panizza M, Nilsson J, Ravazzani P, Grandori F, and Tognola G. 1996. Transverse-field activation mechanism in magnetic stimulation of peripheral nerves. Electroencephalogr Clin Neurophysiol 101:167-174.

Sadik MM, Li J, Shan JW, Shreiber DI, and Lin H. 2011. Vesicle deformation and poration under strong dc electric fields. Phys Rev E Stat Nonlin Soft Matter Phys 83:066316.

Schnabel V, and Struijk JJ. 1999. Magnetic and electrical stimulation of undulating nerve fibres: a simulation study. Med Biol Eng Comput 37:704-709.

Schnabel V, and Struijk JJ. 2001. Evaluation of the cable model for electrical stimulation of unmyelinated nerve fibers. IEEE Trans Biomed Eng 48:1027-1033.

Schwan HP. 1957. Electrical properties of tissue and cell suspensions. Adv Biol Med Phys 5:147-209.

Selimbeyoglu A, and Parvizi J. 2010. Electrical stimulation of the human brain: perceptual and behavioral phenomena reported in the old and new literature. Front Hum Neurosci 4:46. 10.3389/fnhum.2010.00046

Sotiropoulos SN, and Steinmetz PN. 2007. Assessing the direct effects of deep brain stimulation using embedded axon models. J Neural Eng 4:107-119. 10.1088/1741-2560/4/2/011

Stratton J. 1941. Electromagnetic Theory. New York: McGraw-Hill.

Struijk JJ, and Durand DM. 1998. Magnetic peripheral nerve stimulation: axial verses transverse fields. Proceedings BMES/EMBS. Atlanta, 469.

Struijk JJ, and Schnabel V. 2001. Difference between electrical and magnetic nerve stimulation: A case for transverse field. Proceedings of the 23rd Annual International Conference of IEEE, 885-887.

Sturrock RR. 1980. Myelination of the mouse corpus callosum. Neuropathol Appl Neurobiol 6:415-420.

Susil R, Semrov D, and Miklavcic D. 1998. Electric field induced transmembrane potential depends on cell density and organization. Electro Magnetobiol 17:391-399.

Teruel MN, and Meyer T. 1997. Electroporation-induced formation of individual calcium entry sites in the cell body and processes of adherent cells. Biophys $J$ 73:1785-1796. 10.1016/S00063495(97)78209-2 
622 Tyler WJ. 2012. The mechanobiology of brain function. Nat Rev Neurosci 13:867-878. 10.1038/nrn3383

623 Wang B, Aberra AS, Grill WM, and Peterchev AV. 2018. Modified cable equation incorporating

624

625

626

627

628

629

630

631

632

633

634

635

636

637

638

639

640

641

642

643

644

645

646

647

648

649

650

651

652

653 transverse polarization of neuronal membranes for accurate coupling of electric fields. J Neural Eng 15:026003. 10.1088/1741-2552/aa8b7c

Waxman SG, Black JA, Stys PK, and Ransom BR. 1992. Ultrastructural concomitants of anoxic injury and early post-anoxic recovery in rat optic nerve. Brain Res 574:105-119.

While PT, and Forbes LK. 2004. Electromagnetic fields in the human body due to switched transverse gradient coils in MRI. Phys Med Biol 49:2779-2798.

Ye H, Buttigieg J, Wan Y, Wang J, Figley S, and Fehlings MG. 2012. Expression and functional role of BK channels in chronically injured spinal cord white matter. Neurobiol Dis 47:225-236. 10.1016/j.nbd.2012.04.006

Ye H, Cotic M, and Carlen PL. 2007. Transmembrane potential induced in a spherical cell model under low-frequency magnetic stimulation. J Neural Eng 4:283-293. 10.1088/1741-2560/4/3/014

Ye H, Cotic M, Fehlings MG, and Carlen PL. 2011. Transmembrane potential generated by a magnetically induced transverse electric field in a cylindrical axonal model. Med Biol Eng Comput 49:107-119. 10.1007/s11517-010-0704-0

Ye H, Cotic M, Kang EE, Fehlings MG, and Carlen PL. 2010. Transmembrane potential induced on the internal organelle by a time-varying magnetic field: a model study. J Neuroeng Rehabil 7:12. 10.1186/1743-0003-7-12

Ye $\mathrm{H}$, and Curcuru A. 2016. Biomechanics of cell membrane under low-frequency time-varying magnetic field: a shell model. Med Biol Eng Comput 54:1871-1881. 10.1007/s11517-016-1478-9

$\mathrm{Ye} \mathrm{H}$, and Steiger A. 2015. Neuron matters: electric activation of neuronal tissue is dependent on the interaction between the neuron and the electric field. J Neuroeng Rehabil 12:65. 10.1186/s12984-015-0061-1

Yu H, Zheng C, and Wang Y. 2005. A new model and improved cable function for representing the activating peripheral nerves by a transverse electric field during magnetic stimulation. Proceedings of the 2nd International IEEE EMBS Conference on Neural Engineering. Arlington, Virginia.

Zhao H, Steiger A, Nohner M, and Ye H. 2015. Specific Intensity Direct Current (DC) Electric Field Improves Neural Stem Cell Migration and Enhances Differentiation towards betallI-Tubulin+ Neurons. PLoS One 10:e0129625. 10.1371/journal.pone.0129625 


\section{Figure legends}

655 Figure 1. Model setup for a myelin-covered axon (A) and a bare axon (B) under transverse 656 electric field stimulation. The cylindrical coordinate system that was used to define the 657 orientation of the electric field and the axon.

Figure 2. Polarization of a myelin-covered axon (A) and a bare axon (B) in a transverse electric field. The $V m$ was calculated by equations 11 and 13, for the myelin-covered axon and

660

661

662

663

664

665

666

667

668

669

670

671

672

673

674

675

676

677

678

679

680

681 the bare axon, respectively. $\phi$ was calculated by equation 12 . All calculations were based on the standard parameters in Table 1. The color maps represented the amount of polarization (in $\mathrm{mV}$ ). (C) Effect of transverse electric field intensity on axonal polarization in myelin-covered and bare axons. (D) Log plot of (C).

Figure 3. Dependency of $V \boldsymbol{m}$ on the biophysics properties of the axon. (A) Axolemma diameter. (B) Axolemma thickness. (C) Axolemma conductivity.

Figure 4. Effects of decreased myelin thickness on axonal polarization. Reduction of myelin thickness from $3.4 \mu \mathrm{m}$ to $0.1 \mu \mathrm{m}$ (and linear increase of its conductivity) caused a significant reduction in $\phi$, but not $V m$. For the inset example, axon diameter $=0.6 \mu \mathrm{m}$. Myelin thickness $=0.1$ $\mu \mathrm{m}$.

Figure 5. Effects of a leaky myelin sheath on axolemma polarization in a transverse electric field. Conductivity of each myelin layer was (A) $5 \times 10^{-5} \mathrm{~S} / \mathrm{m}$, (B) $5 \times 10^{-3} \mathrm{~S} / \mathrm{m}$, and (C) $5 \times 10^{-1} \mathrm{~S} / \mathrm{m}$, respectively. For the inset two examples, axon diameter $=0.6 \mu \mathrm{m}$. Myelin diameter $=0.7 \mu \mathrm{m}$ and $4.6 \mu \mathrm{m}$, respectively.

\section{List of additional files:}

Supplementary file 1 [Mathematic derivations for potential distributions in the five modeled regions in myelin-covered axon (equation 9), and the transmembrane membrane potential $\mathrm{Vm}$ (equation 11).]

Supplementary file 2 [Mathematic derivations for $\phi$ for the myelin sheath (equation 12).]

Supplementary file 3 [Mathematic derivations for $V m$ in the bare axon (equation 13).] 
Figure 1

Model setup for a myelin-covered axon (A) and a bare axon (B) under transverse electric field stimulation.

The cylindrical coordinate system that was used to define the orientation of the electric field and the axon.

A

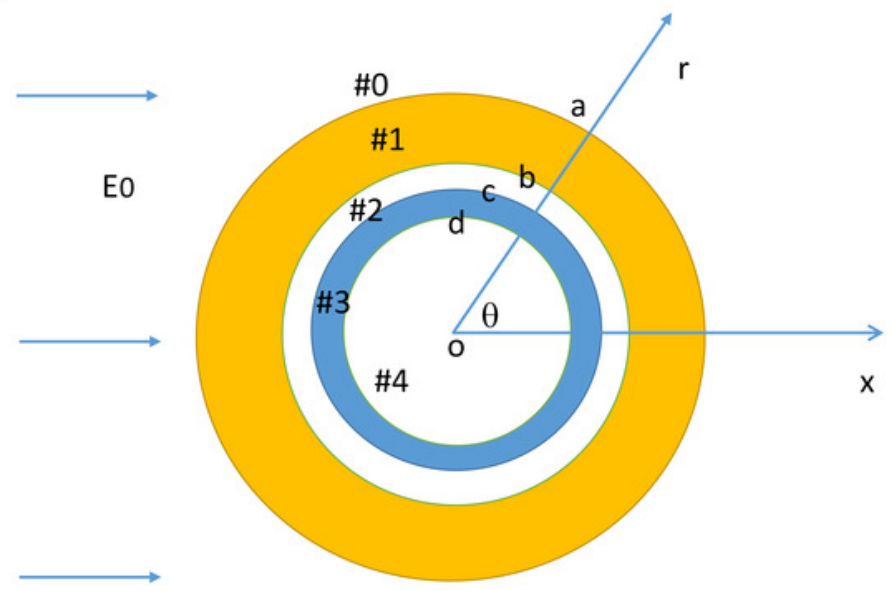

B

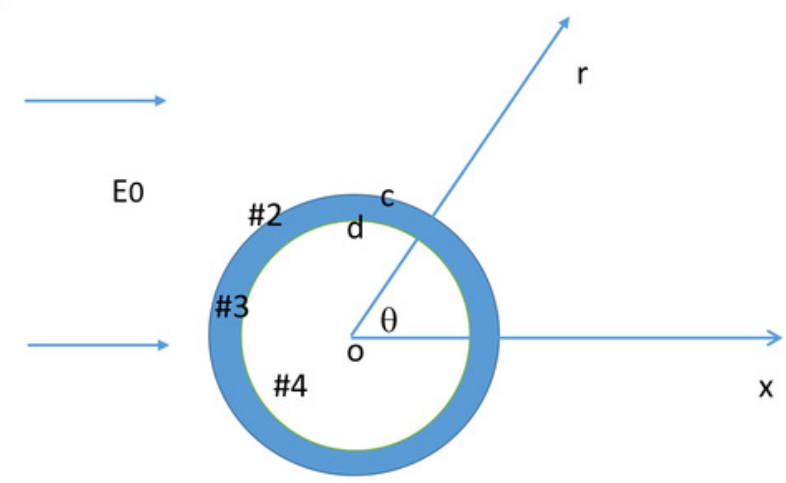




\section{Figure 2}

Polarization of a myelin-covered axon $(A)$ and a bare axon $(B)$ in a transverse electric field.

The $V m$ was calculated by equations 11 and 13 , for the myelin-covered axon and the bare axon, respectively. $f$ was calculated by equation 12 . All calculations were based on the standard parameters in Table 1. The color maps represented the amount of polarization (in $\mathrm{mV}$ ). ( C ) Effect of transverse electric field intensity on axonal polarization in myelin-covered and bare axons. ( D ) Log plot of (C).
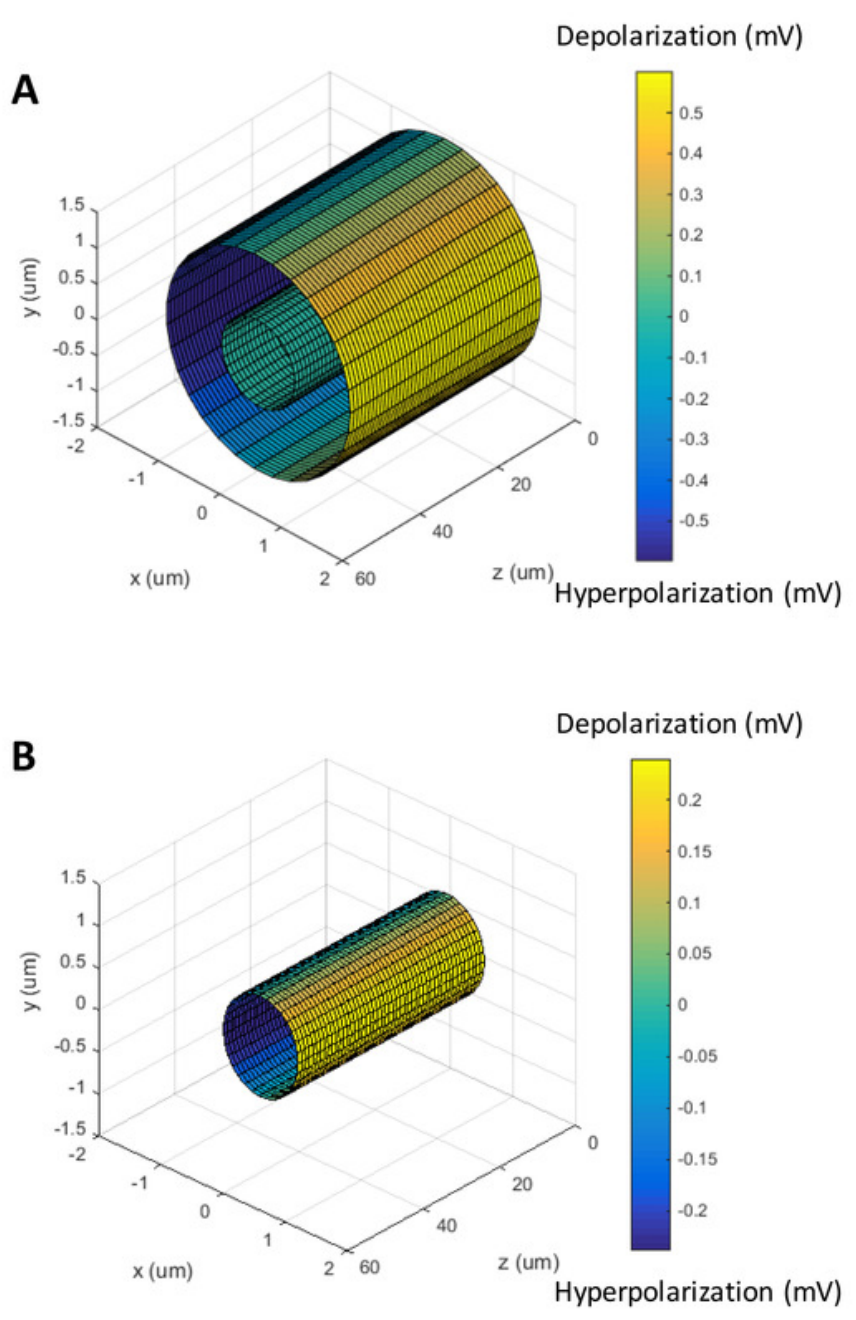

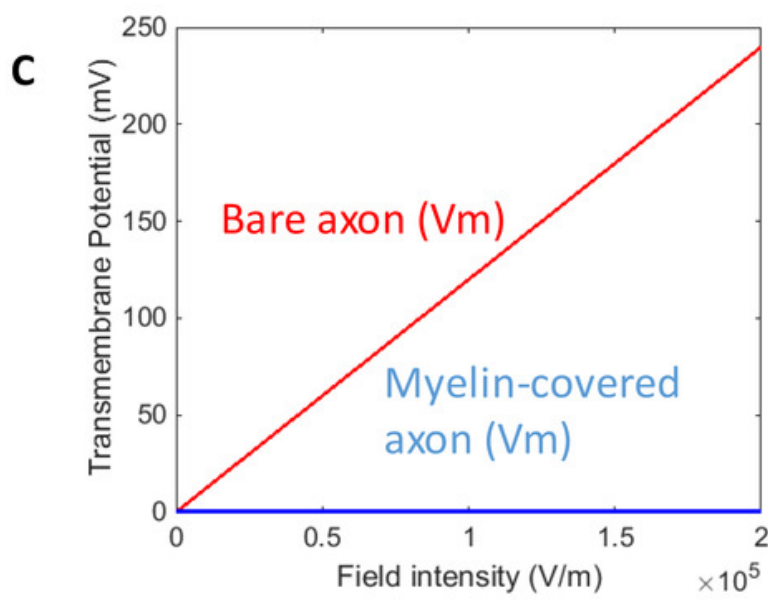

D

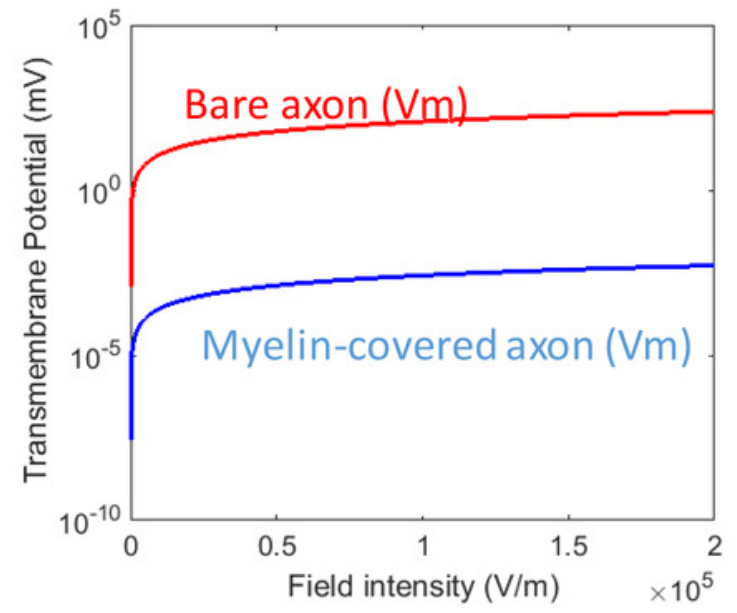


Figure 3

Dependency of $V m$ on the biophysics properties of the axon.

( A ) Axolemma diameter. ( B ) Axolemma thickness. ( C ) Axolemma conductivity.
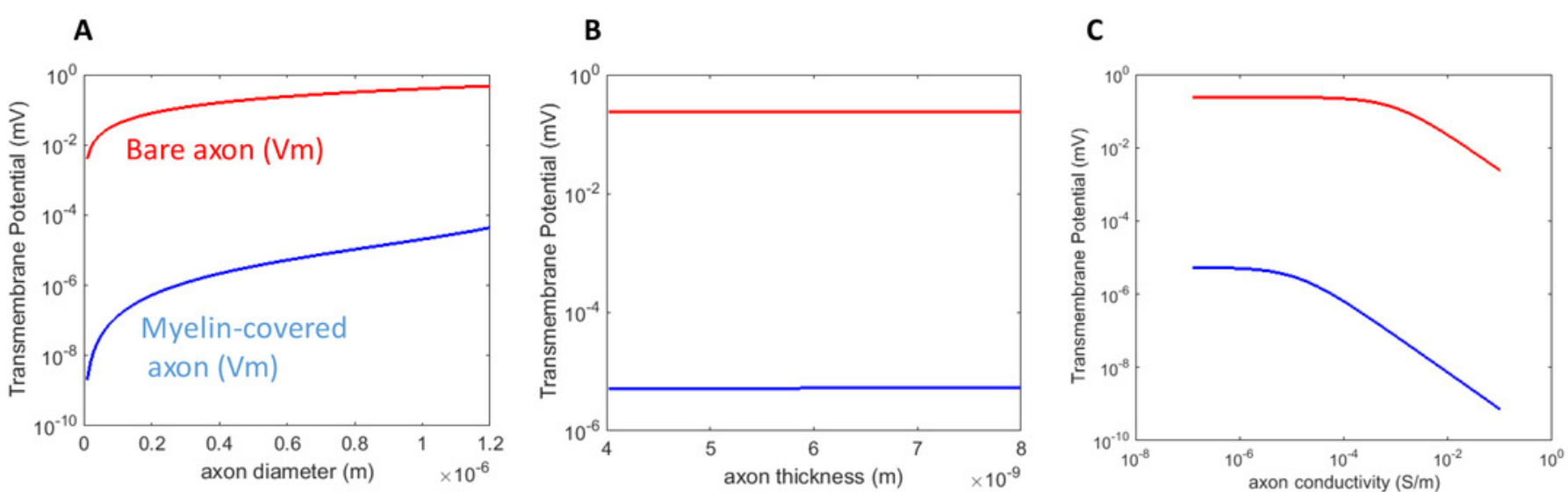


\section{Figure 4}

Effects of decreased myelin thickness on axonal polarization.

Reduction of myelin thickness from $3.4 \mu \mathrm{m}$ to $0.1 \mu \mathrm{m}$ (and linear increase of its conductivity) caused a significant reduction in $f$, but not $V m$. For the inset example, axon diameter $=0.6$ $\mu \mathrm{m}$. Myelin thickness $=0.1 \mu \mathrm{m}$. 


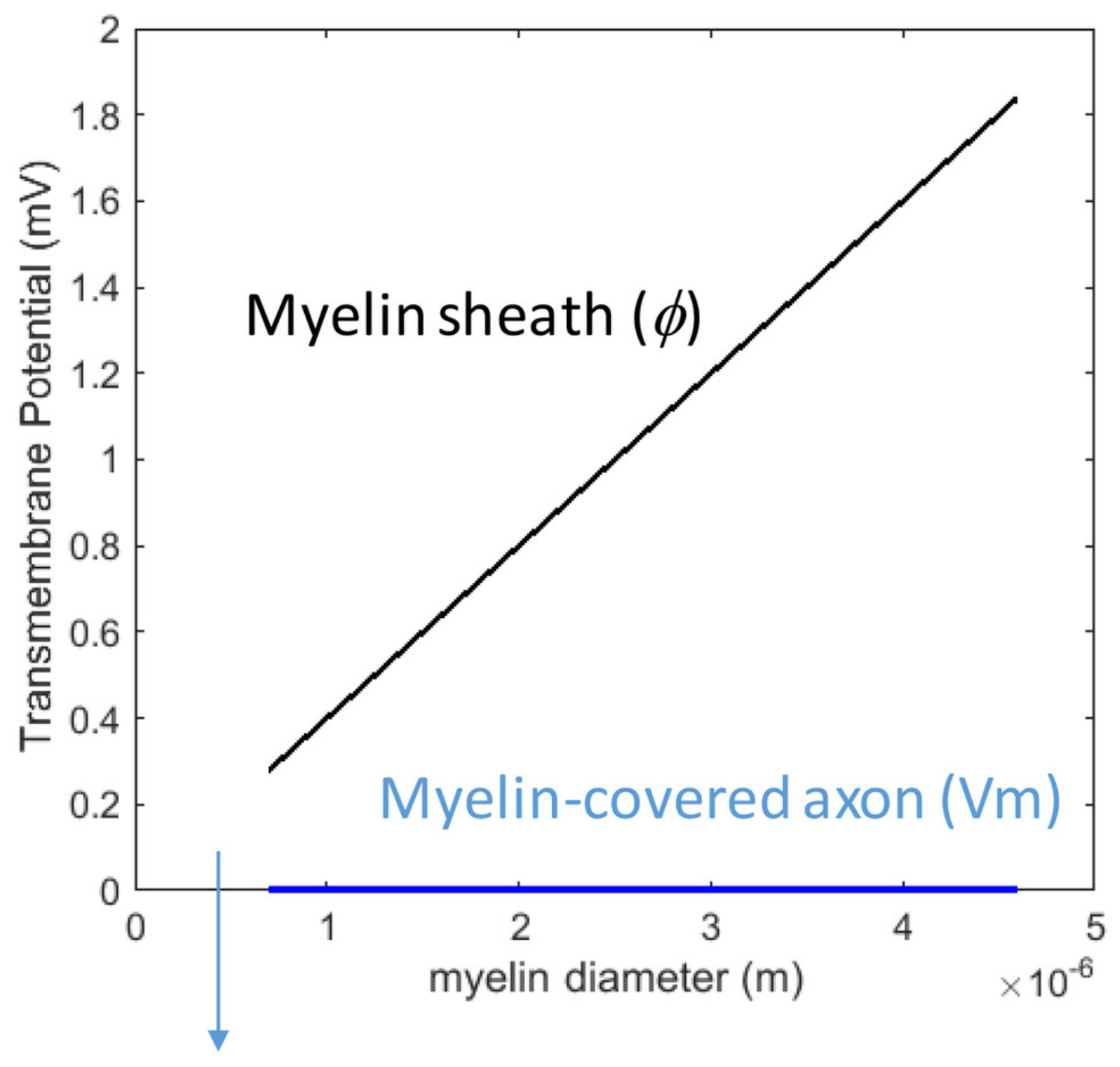

Depolarization $(\mathrm{mV})$
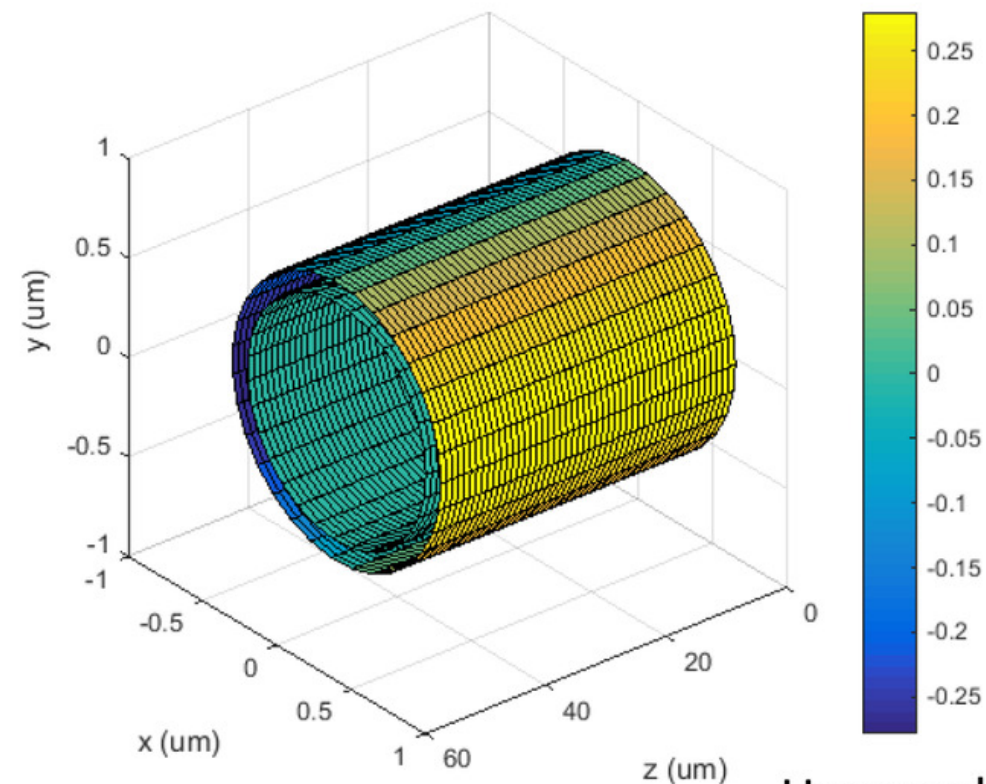
Figure 5

Effects of a leaky myelin sheath on axolemma polarization in a transverse electric field.

Conductivity of each myelin layer was (A) $5^{\prime} 10^{-5} \mathrm{~S} / \mathrm{m}$, (B) $5^{\prime} 10^{-3} \mathrm{~S} / \mathrm{m}$, and (C) $5^{\prime} 10^{-1}$ $\mathrm{S} / \mathrm{m}$, respectively. For the inset two examples, axon diameter $=0.6 \mu \mathrm{m}$. Myelin diameter $=$ $0.7 \mu \mathrm{m}$ and $4.6 \mu \mathrm{m}$, respectively.
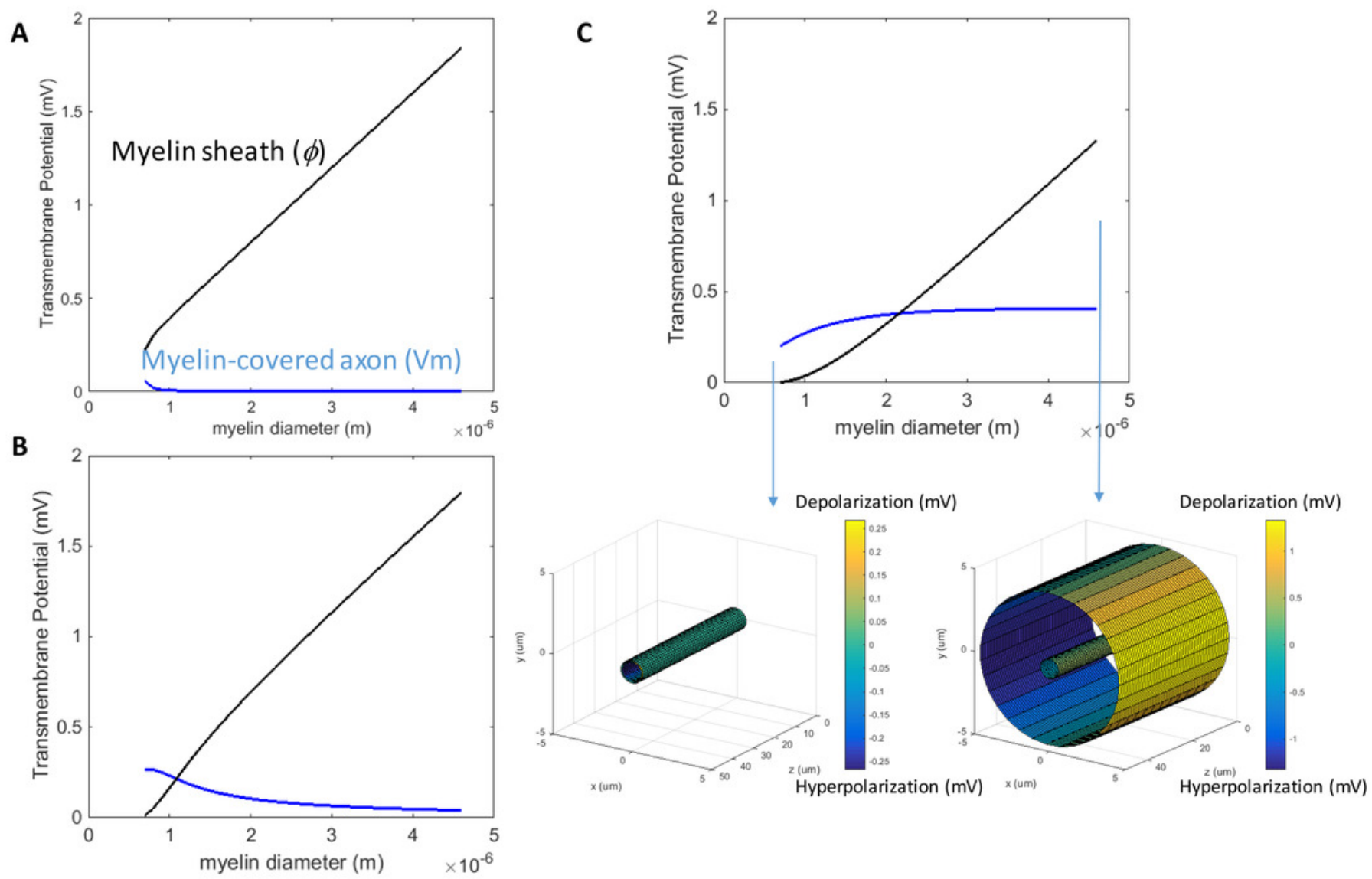
Table $\mathbf{1}$ (on next page)

Model parameters. 


\section{Parameters}

Extracellular conductivity $\left(\sigma_{0}, \mathrm{~S} / \mathrm{m}\right)^{\mathrm{a}, \mathrm{b}}$

Myelin conductivity $\left(\sigma_{1}, \mathrm{~S} / \mathrm{m}\right)^{\mathrm{a}, \mathrm{b}}$

Periaxonal conductivity $\left(\sigma_{2}, \mathrm{~S} / \mathrm{m}\right)^{\mathrm{a}, \mathrm{b}}$

Axonal conductivity $\left(\sigma_{3}, \mathrm{~S} / \mathrm{m}\right)^{\mathrm{a}, \mathrm{b}}$

Cytoplasmic conductivity $\left(\sigma_{4}, \mathrm{~S} / \mathrm{m}\right)^{\mathrm{a}, \mathrm{b}}$

\section{Standard value Lower limit Upper limit}

0.2

$5 \times 10^{-4}$

2.0

Extracellular dielectric permittivity $\left(\varepsilon_{0}, \mathrm{As} / \mathrm{Vm}\right)^{\mathrm{a}, \mathrm{b}}$

$5.0 \times 10^{-7} / \mathrm{n}^{\mathrm{g}}$

$1.0 \times 10^{-8} / \mathrm{n}$

$1.2 \times 10^{-6} / \mathrm{n}$

0.2

$2.0 \times 10^{-2}$

1.0

$5.0 \times 10^{-7}$

$1.0 \times 10^{-8}$

$1.2 \times 10^{-6}$

0.2

$2.0 \times 10^{-2}$

1.0
$6.4 \times 10^{-10}$
$3.5 \times 10^{-10}$
$7.0 \times 10^{-10}$
Myelin dielectric permittivity $\left(\varepsilon_{1}, \mathrm{As} / \mathrm{Vm}\right)^{\mathrm{a}, \mathrm{b}}$
$4.4 \times 10^{-11}$

Periaxonal dielectric permittivity $\left(\varepsilon_{2}, \mathrm{As} / \mathrm{Vm}\right)^{\mathrm{a}, \mathrm{b}}$

$$
3.5 \times 10^{-10} \quad 7.0 \times 10^{-10}
$$

$$
6.4 \times 10^{-10}
$$

Axonal myelin dielectric permittivity $\left(\varepsilon_{3}, \mathrm{As} / \mathrm{Vm}\right)^{\mathrm{a}, \mathrm{b}}$

$1.8 \times 10^{-11} \quad 8.8 \times 10^{-11}$

$$
4.4 \times 10^{-11}
$$

$1.8 \times 10^{-11} \quad 8.8 \times 10^{-11}$

$$
6.4 \times 10^{-10}
$$

Cytoplasmic dielectric permittivity $\left(\varepsilon_{4}, \mathrm{As} / \mathrm{Vm}\right)^{\mathrm{a}, \mathrm{b}}$

$$
3.5 \times 10^{-10} \quad 7.0 \times 10^{-10}
$$

Myelin diameter (a, nm)

\section{5}

b. Axonal membrane thickness $(\mathrm{nm})^{\mathrm{c}}$

6

0.7

4.6

Axonal radius $(\mathrm{c}, \mu \mathrm{m})^{\mathrm{d}}$

0.6

0.1

1.2

Periaxonal space width $(\mu \mathrm{m})^{\mathbf{e}}$

0.004

0.004

0.004 


\begin{tabular}{llll}
\hline Number of myelin layers (n) & & 0 & 40 \\
\hline Electric field intensity $(\mathrm{V} / \mathrm{m})$ & 40 & 0 & $200000^{\mathbf{h}}$
\end{tabular}

$1 \quad$ a (Kotnik et al. 1997).

$2 \quad \mathrm{~b}$ (Kotnik \& Miklavcic 2006).

$3{ }^{\mathrm{c}}$ (Nagarajan \& Durand 1995).

$4 \quad$ d (Berthold \& Rydmark 1995).

5 e (Berthold et al. 1983).

6 f (Ruff et al. 2013).

7 g (Chomiak \& Hu 2009).

8 h (Sadik et al. 2011).

9

10 Table 1. Model parameters. 